\title{
PROJECT-BASED KNOWLEDGE MANAGEMENT SYSTEM USING BLOG
}

\author{
Changbum Ahn \\ M.Sc Student, Dept. of Architecture \\ Seoul National Univ., Seoul, 151-742, Korea \\ acb1229@snu.ac.kr \\ Hyun-Soo Lee \\ Professor, Dept. of Architecture \\ Seoul National Univ., Seoul, 151-742, Korea \\ hyunslee@snu.ac.kr
}

\author{
Moonseo Park \\ Associate Professor, Dept. of Architecture, \\ Seoul National Univ., Seoul, 151-742, Korea \\ mspark@snu.ac.kr \\ Seungjun Roh \\ Researcher, Dept. of Architecture \\ Seoul National Univ., Seoul, 151-742, Korea \\ rohsj97@snu.ac.kr
}

\begin{abstract}
Knowledge management (KM), through learning from past projects, has been considered as an effective means for continuous improvement. However, many KM initiatives have failed to meet this expectation, due to the top-down, controlled approach and an ineffective transferring mechanism.

To address this challenging issue, this paper proposes a project-based KM system that helps to acquire and transfer knowledge, using blogs on a project basis instead of knowledge maps. Project blogs store various types of project information and knowledge including communications among project participants, and interconnecting personal blogs of project participants with project blogs would improve collaboration between project participants. Moreover, the proposed KM system could realize "information pulling" of lean construction by delivering prerequisite knowledge of an activity at the time that project participants are ready for that activity. Stored knowledge, with the contextual information extracted from the schedule database, is automatically "pulled" to project participants
\end{abstract}

\section{KEY WORDS}

Knowledge Management, Project-Based, Blogs, Information Pulling

\section{INTRODUCTION}

The term "Knowledge Management (KM)" is no longer new to the construction organizations. A survey of 170 construction organizations (consultants and contractors) in the United Kingdom shows that about $40 \%$ of them already had a KM strategy, and another $41 \%$ had plans to develop a strategy in one year (Robinson et al. 2001). As the Korean construction industry is no exception, many Korean construction firms are also trying to institute their own KM system to gain and sustain competitive advantage (Baik 2003).

The KM system (KMS), a system for managing knowledge, is one of the most promising strategic information systems for construction companies. However, current KMSs have not been able to meet engineers' needs on the job site, as those systems have attempted to encompass almost all aspects of construction processes and all types of information, making the systems difficult to use and resulting in a very low frequency of use (Jung et al. 2006). Another survey of UK construction organizations, conducted by Egbu and Botterill (2002), pointed out that general tools in KMS such as Knowledge-based Expert Systems, Communities of Practice, and Decision support systems, ranked low in usage and effectiveness scores among 25 tools for KM, even though conventional IT implementations such as Internet/Intranet and IT-based database ranked high. 
The causes of the low usage and ineffectiveness of current KMSs are largely of two types: inherent problems in the system, and managerial problems in the organization. This paper, focusing on the former type, proposes a system that resolves the inherent problems in current KMSs.

\section{REALITY OF OPERATING KNOWLEDGE MANAGEMENT SYSTEM IN CONSTRUCTION}

In order to identify the reality of operating KMS in construction, we first reviewed the case studies on KM practices in the Korean construction sector and selected three firms, the KMSs of which contain the main features of the KM system functions and architectures that are prevalent in the construction industry.

We conducted case studies by in-depth interviews and observation of users' behavior. The interviews were conducted with the managers of the KM organization of each firm, and enabled us to determine the system architecture of KMS, the KM performance and its problems from the point of view of administrators. The observation of users' behavior was conducted at company headquarters and construction sites. We visited the selected users' workplaces and observed their KM activities, such as inputting knowledge, searching knowledge and reusing knowledge, through the KMSs of their firms. These observations indicated the difficulties that they confronted in each of their KM activities.

\subsection{System Architecture of Current Knowledge Management Systems}

The systems of all three companies are composed of three functional modules for executing knowledge mapping, knowledge searching and knowledge evaluation, respectively. The knowledge mapping module creates and stores knowledge. In this module, knowledge inputted by employees is stored in its category, which is classified by the relevant working process or the type of knowledge. In the knowledge searching module, a user can search necessary knowledge by inputting relevant keywords into the search engine. The evaluation process module supports knowledge validating and maintenance, as playing an important role in motivating employees to create knowledge by converting knowledge into a quantitative score in their respective evaluations.

Under this architecture, system users register knowledge after selecting its appropriate category, and the applicability and correctness of the knowledge are evaluated by the knowledge master of its category. The evaluated knowledge can be accessed by narrowing down knowledge maps or using the knowledge searching module. Knowledge Evaluation scores are accumulated by unit individuals and teams, and are used for estimating the KM activities of those individuals or teams.

\subsection{Problems of Current Knowledge Management Systems}

The case studies showed that all of the companies were dissatisfied with the usage and effectiveness of their KM systems. A thorough investigation of the system users' behaviors revealed that the low usage and effectiveness of the current system were mainly due to the following reasons related to capturing, sharing and transferring knowledge.

\subsubsection{Capturing}

The organization grants incentives to its employees according to the knowledge activities score of individuals and teams, or compels its employees to meet a minimum knowledge activities score. Although the purpose of such policies is to increase the quantity of knowledge, those policies increase only perfunctory knowledge creation, which causes deterioration in knowledge quality. The deteriorated knowledge quality reduces users' satisfaction, and accordingly usage of the system. Moreover, incentives or compulsions make employees consider knowledge activities as entailing an additional significant workload. As a result, employees come to be reluctant to use KMS. Therefore, it can be inferred that a controlled and top-down system approach hinders voluntary knowledge activities within the organization.

\subsubsection{Storing}

Knowledge that users acquire from the system includes only limited information on knowledge context. The contextual information provided in the system is limited to the name of the creator, the department and the created time. However, in order to effectively apply certain knowledge to the 
project, detailed situational information of the project is needed, such as a project description, the associated activity, the involved companies as well as the relevant knowledge that was created earlier. In order both to fully understand the knowledge and to engender confidence in the credibility of the knowledge, what is also required is detailed information from the knowledge creator, such as his or her work experience, skills, and the knowledge description level. This knowledgecontextual information certainly exists at the time of creation, but tends to be lost in the process of storing knowledge.

\subsubsection{Transferring}

The system includes two manual knowledge transfer methods: searching, and narrowing down knowledge maps. Both methods are efficient from the standpoint of system resources, because knowledge is delivered on the user's demand. However, they are inefficient in that the users' time and effort are required. Moreover, this inefficiency is the main reason that employees choose other, simpler KM techniques such as telephoning and face-to-face meetings, despite their high recognition of the quantity and quality of the knowledge available in the KM system. Moreover, those other, simpler methods serve to keep users in a state of low recognition of their knowledge needs.

\section{PROJECT-BASED APPROACH TO KNOWLEDGE MANAGEMENT}

In order to address these challenging issues, a project-based KMS is suggested. Whereas the conventional KMS focuses on organizational knowledge, handling KM processes on the basis of each department of the organization, the proposed new system focuses on project knowledge, entailing the execution of all of the KM processes on the basis of each project. All of the knowledge created during the project is stored in a projectspecific knowledge repository along with project information, and this enables the automatic transfer of requisite knowledge to participants of other projects based on project-contextual information. This project-based approach entails three implementation mechanisms, each of which overcomes impediments to KM processes in the conventional KMS.

\subsection{Adapting Blogs}

'Blogs' are user-generated websites that display journal-style entries in a reverse chronological order (Blog 2007). They are easily set up, maintained and contributed to by a broad network of loosely associated individuals. Blogs were originally used as private media, but recently they have been recognized as powerful KM tools by practitioners who have observed the enormous knowledge that blogs have produced and the expansive social networks that they interconnect. Blog-adapted practices have already been introduced in other industries. For instance, IBM allows its employees in 30 global branches to discuss software development process and business strategies in their blogs (Lee et al. 2005).

Adapting blogs to construction KM has already been addressed conceptually by Mills (2006). First, he identifies that construction is essentially a people-focused enterprise that engages formal and informal networks that must share knowledge in order to succeed. This people-centered aspect of knowledge sharing in the construction industry is also addressed by Cleveland (1999) and Chinowsky and Molenaar (2005). Second, Mills argues that blogs, as people-centric tools entailing user-driven social networks, represent a democratic, bottom-up approach to KM implementation in construction that helps to remove obstacles caused mainly by rigidly controlled, top-down approaches.

The project-based approach adapts blogs to a personal knowledge repository as well as a projectknowledge repository. The impediment in the capturing process of the conventional approach would mostly be solved by the adaptation of blogs, which encourage voluntary knowledge creation. As a result, we expect that the open and democratic aspects of blogs would change the conventional approach's loop effect, which controls all KM activities by incentives and compulsion.

\subsection{Contextual Knowledge Management}

Context is defined as the aggregate relevant conditions and surrounding influences that make a situation unique and comprehensible (Anderson, 1995). According to Goldkuhl and Braf (2000), contextual knowledge encompasses the 


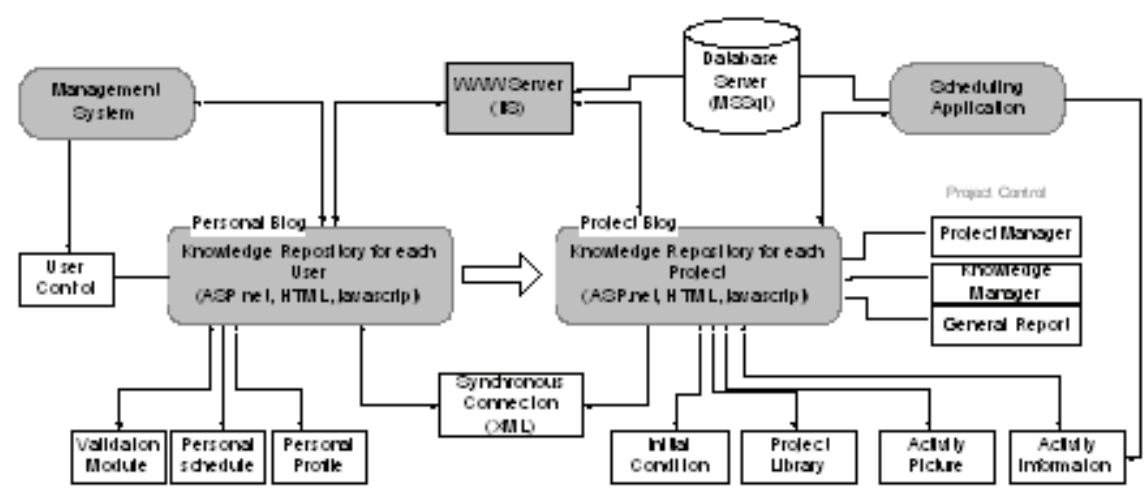

Figure 1 Contextual Knowledge Management System Architecture

organizational situations in which knowledge is created, transferred and utilized, and enables people to reuse knowledge by allowing them to apply knowledge from a similar or analogous past situation to a current situation. .He argues that contextual knowledge is mainly composed of both situational knowledge, which is derived from actual situations as well as earlier knowledge concerning similar situations, and trans-situational knowledge, which can be generalized knowledge abstracted from earlier situations and particular experiences (memories) from those earlier situations. In regard to construction knowledge, situational knowledge could be considered to be the environment and situational information of the project, and trans-situational knowledge could be considered to be the project participants' experiences and knowledge from earlier projects as well as their understanding of the specific knowledge. Only when such contextual knowledge is provided can specific knowledge from a particular situation be reused. Moreover, a reuser's understanding of specific knowledge can be improved.

In order to provide this contextual knowledge in construction, we present a blog-adapted system architecture (Figure 1). As shown in Figure 1, a personal blog, as a knowledge repository for each user, plays a role in delivering trans-situational knowledge. Trans-situational knowledge could be captured in rich personal information representing a blog creator's whole career and skills, and could also be acquired from a blog creator's awareness of certain specific knowledge, which is reflected in his or her earlier knowledge as well as others' evaluation of and comments on that knowledge. A project blog, a knowledge repository for each project, plays a role in delivering situational knowledge. In order to deliver situational knowledge, activity-related knowledge is associated with its activity information so that when it is delivered, detailed information on related activities such as the activity description, start date, completion date, and companies involved, as well as detailed project information such as the location, type of project, duration and type of contract, can be delivered together.

A project blog would also perform functions as project-specific web sites, forums for collaboration among project participants. It could store various types of project-related information with schedule information, and so it could also provide information and knowledge relevant to a specific activity. Moreover, using trackback or comments, it could capture live communication among participants about specific knowledge.

\subsection{Information Pulling}

Thorpe and Mead (2001) define the pull model of information as delivering "just-in-time" information characterized by in-phase timing, low volume, user-selected data, and a project focus, whereas the traditional push model handles just-incase information characterized by out-of-phase timing, high volume, irrelevant data, and an organizational focus. On this basis, we define "information pulling" as delivering prerequisite knowledge of the successor activity at the time that project participants are ready for that activity. The 
key purpose in "information pulling" is to make the information system know when to deliver prerequisite knowledge for a succeeding activity.

In information pulling, the proposed system utilizes knowledge context to determine the time of and prerequisite knowledge for each activity. Activity is the key component of knowledge context. From the project scheduling application, we can extract activity information. Activity WBS, CBS, and OBS information impart the characteristics of work information to the knowledge context. In the knowledge context, a personal profile is also important in categorizing users who receive knowledge. Keywords extracted from inputted knowledge are also stored in the knowledge context. This knowledge context is then stored with the knowledge in the database.

Such accumulated knowledge, with activity contextual information extracted from the project scheduling application, is automatically delivered to other users facing a similar activity in a new project. The delivery process is performed in the following four steps: (1) the system notes, from the database of the project scheduling application, the fact that the start date of the successor activity is close at hand; (2) the context of the successor activity is extracted from the project scheduling application, and then the knowledge context is created; (3) knowledge from similar activities in finished projects is searched from knowledge databases, using the knowledge context created in the previous step; (4) extracted knowledge is transferred to a user by e-mail. This flow of storing and delivering knowledge in information pulling is illustrated in Figure 2.

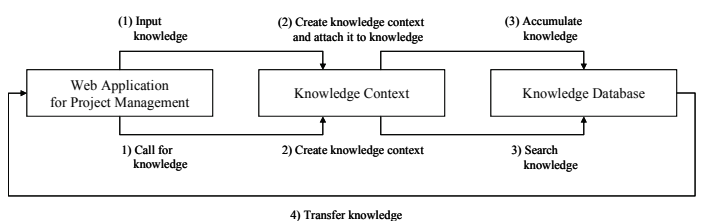

Figure 2: Flow of Knowledge Storage and Knowledge Delivery in Information Pulling

\section{CONCEPTUAL MODEL FOR INDUSTRY-WIDE SHARING}

In order to facilitate knowledge sharing in smallto-medium enterprises (SMEs), we propose a web portal to extend the project-based KM system.
Through this portal, the functions of the projectbased KMS are provided to SMEs using ASP. Because insufficient funding is the most critical obstacle to implementing KM in SMEs, and as ASP is the lowest-cost option among KMS strategies, using ASP could encourage SMEs to implement KM. In addition, individual engineers can also participate in knowledge sharing by creating a personal blog in the portal.

The main purpose of this portal is to broaden SMEs' knowledge-sharing networks by facilitating knowledge sharing between SMEs, thereby enhancing the limited scope of SMEs' knowledgesharing networks. For this purpose, each SME needs to allow some knowledge stored in the project-based KMS to be shared with other participating SMEs. When the project is initiated, managers set up a critical process and knowledge mapping. Participants in each project have their own blogs that are used as personal and projectknowledge repositories. Individual users should sign on to this portal and keep personal blogs, like SME members, and are given access to the opento-the-public knowledge database. Users can find the knowledge they need at any time through a knowledge search.

These knowledge-sharing networks among SMEs would be very effective in disseminating best practices. If a finished project is evaluated as a best practice, just allowing the project blog of a best practice to be accessible to other SMEs in the portal could provide live knowledge and vivid recordings of the project. As mentioned above, a project blog could capture even the communication between project participants so that not only the outline and result of the best practice, but also more in-depth insight into the best practice could be provided to members through the portal.

\section{CONCLUSIONS}

We determined, from the results of in-depth case studies of practices within the Korean construction sector, that the main causes of the low usage and effectiveness of conventional KMS are inherent in each of the existing $\mathrm{KM}$ processes. In the knowledge-capturing process, the controlled and top-down approach of the system hinders voluntary knowledge creation in the organization, the result being that knowledge context is left out of the knowledge-storing process. Additionally, 
the knowledge-transfer process relies entirely on manual methods that can provide information only in response to users' demands.

The proposed project-based KMS uses blogs as a knowledge repository tool for individuals and projects in order to exploit the blogs' advantages in motivating knowledge creation. When knowledge is delivered, this system simultaneously provides rich contextual knowledge from the project and personal blogs together, which enhances the understanding of the knowledge and provides a basis of decision-making in the reusability of the knowledge of a particular situation. Moreover, this system realizes "information pulling", which entails the automatic delivery of prerequisite knowledge for a succeeding activity, using the contextual information extracted from the project scheduling application. This system is expected to facilitate the increased reuse of appropriate knowledge and the strengthening of the positive feedback loop of $\mathrm{KM}$, through motivating more users to use the system as voluntary creators of knowledge.

Furthermore, the conceptual model of the portal was introduced in order to extend this approach to SMEs and facilitate their knowledge sharing. Indeed, SMEs can expand their knowledge sharing and transferring by using the portal's ASP.

\section{ACKNOWLEDGMENTS}

The authors would like to acknowledge the support for this research from the Korean Ministry of Construction and Transportation, Research Project 05 CIT D05-01.

\section{REFERENCES}

[1] Anderson J. (1995). Language, Memory and Thought. New Jersey, Erlbaum.

[2] Baik, J. and Kim, J. (2003). "Implementing Knowledge Management (KM) for a competitive enhancement in Construction Company." AIK, Journal of Architectural Institute of Korea, 19(3).

[3] Blog (2007). Blog In Wikipedia. The Free Encyclopedia

$<$ http://en.wikipedia.org/w/index.php?title=Blo g\&oldid=122753081 $>$ (Apr. 14, 2007).

[4] Chinowsky, P. and K. Molenaar (2005). "Learning Organizations in Construction."
Construction Research Congress 2005, San Diego, California.

[5] Cleveland, J. A. B. (1999). "Knowledge Management: Why It's Not an Information Technology Issue." Journal of Management in Engineering, 15(6) 28-28.

[6] Egbu, C. O. and Botterill, K. (2002). "Information technologies for knowledge management: their usage and effectiveness." Electronic Journal of Information technology in Construction, 7 (1) 125-137.

[7] Goldkuhl, G. and Braf, E. (2001), "Contextual Knowledge Analysis - Understanding Knowledge and Its Relations to Action and Communication", The 2nd European Conference on Knowledge Management, IEDCBled School of Management, Slovenia.

[8] Hopp, W. and Spearman, M. (1996). Factory Physics. McGraw Hill Higher Education, Columbus, 317 pp.

[9] Jung, Y. S., Kang, S. H., Choi, I. S.(2006), "Strategic Knowledge Management for Building Engineering and Construction", AEI 2006, Omaha, Nebraska, USA

[10] Khalfan, M. M. A., Bouchlaghem, N. M., Anumba, C. J., and Carrillo, P. M. (2003). "Knowledge Management for Sustainable Construction: The C-CanD Project." Construction Research Congress In Construction, Honolulu, Hawaii, USA.

[11]Lee, J., Kang H., Jung T., Seo J. (2005). "The Business Management in the Blog Age." Samsung Economic Research Institute, issue 526.

[12]Mills, T. (2007), "Wiki-based Construction Knowledge Sharing", The ASC Annual Conference, Associated Schools of Construction, Flagstaff, Arizona.

[13] Robinson, H. S., Carrillo, P. M., Anumba, C. J., and Al-Ghassani, A. M. (2001). "Perception and barriers in impelementing knowledge management strategies in large construction organizations." Proc., Royal Institution of Chartered Surveyors COBRA conf., London, 451-460.

[14] Thorpe, T. and Mead, S. (2001). "ProjectSpecific Web Sites: Friend or Foe?" ASCE, J. Constr. Engrg. and Mgmt., 127(5) 406-413 